\title{
INCLUSÃO, INTERCULTURALIDADE'1 E DECOLONIALIDADE: quando as questões de raça, gênero e classe social interrogam as práticas docentes
}

\author{
Camila Nagem Marques Vieira² \\ Paulo Melgaço da Silva Junior 3 \\ Maria Vitória Campos Mamede Maia4
}

\section{RESUMO}

Este artigo tem por objetivo discutir os conceitos de inclusão, interculturalidade e decolonialismo a partir de situações vividas por dois professores de artes visuais, também autores deste artigo, os quais buscam, em seus contextos pedagógicos, fomentar a reflexão de seus alunos para derenraizamento de práticas culturais subalternizantes. A metodologia utilizada é a pesquisa-ação, já que é a partir das situações emergentes em sala que se estabelecem as categorias de pesquisa e a ação interventiva capazes de provocar mudanças nos sujeitos, promovendo a inclusão e o respeito às diferenças. A partir do exposto, pode-se concluir que, no imaginário social ainda vigente na sociedade brasileira, ainda há um caminho difícil de conscientização em relação às questões raciais e de que maneira estas se veem incluídas nos currículos e práticas dos docentes da educação básica. Assim, defende-se a importância de questionar e desessencializar visões e discursos congelados sobre raça e gênero no ambiente escolar, seja qual for a faixa etária dos alunos, pois se trata de estimular a desidentificação. A promoção do reconhecimento das diferenças presentes no cotidiano escolar necessita ser entendida como possibilidade de enriquecimento dos saberes e trocas de experiências escolares. Para tanto, é interessante que haja nas instituições escolares uma constante revisão das relações entre seus atores, da seleção de currículos e da

\footnotetext{
${ }^{1}$ Como opção didática utiliza-se aqui o termo interculturalidade, apesar da polissemia dos termos inter, multi, pluriculturalidade. Resgata-se que não existe consenso na literatura sobre o tema, havendo diferentes interpretações dessa expressão, destacando pontos que se assemelham e se contrapõem (CANDAU, 2010).

2 Doutorado em Educação pela UFRJ. Professora de Artes Visuais e do Curso de Especialização em Ensino de Artes Visuais do Colégio Pedro II. Pesquisadora do LUPEA (PPGE/UFRJ). Rio de Janeiro, RJ, Brasil. Orcid iD: https://orcid.org/0000-0003-4987-2953. E-mail: nagem.camila@gmail.com

3 Pós-Doutorado e Doutorado em Educação pela UFRJ/RJ. Secretaria Municipal de Educação de Duque de Caxias/RJ. Professor Colaborador do Programa de Pós-Graduação em Artes Cênicas (PPGEAC) da UNIRIO/RJ. Rio de Janeiro, RJ. Orcid iD: http://orcid.org/00000002-4301-9305. E-mail: pmelgaco@vol.com.br

4 Pós-Doutorado em Design e Doutorado em Psicologia pela PUC/RJ. Professora colaboradora do Programa em Pós-Graduação em Educação (PPGE/UFRJ), Coordenadora do LUPEA (PPGE/UFRJ). Rio de Janeiro, RJ. Orcid iD: https://orcid.org/0000-0002-9697-8243. Email: mariavitoriamaia@gmail.com
} 
didática para que estes rompam com o universalismo e o eurocentrismo, de maneira que o processo de inclusão das diferenças oriente e elabore novos saberes e possibilidades de aprendizagem.

Palavras-chave: Inclusão. Interculturalidade. Práticas culturais subalternizantes.

\author{
INCLUSION, INTERCULTURALITY AND DECOLONIALITY: \\ When questions of race, gender and social class interrogate teaching \\ practices
}

\begin{abstract}
This article aims to discuss the concepts of inclusion, interculturality and decoloniality based on situations experienced by two visual arts teachers, who seek in their pedagogical contexts to foster their students' reflection in order to freeze subalternization cultural practices. The methodology used is action research, since it is from the emergent situations in the classroom that the research categories and interventional action capable of causing changes in the subjects are established, promoting inclusion and respect for differences. From the above, it can be concluded that in the social imaginary still prevailing in Brazilian society, there is still a difficult way of raising awareness regarding racial issues and how they are included in the curriculum and practices of teachers of basic education. Thus, we defend the importance of questioning and denializing frozen visions and discourses about race and gender in the school environment, whatever the age range of the students, because it is about promoting deidentification. The promotion of recognition of the differences present in daily school life should be understood as a possibility of enriching knowledge and exchanging school experiences. To this end, there must be a constant review of the relationships between their actors, the selection of curricula and didactics in schools to break with universalism and eurocentrism, so that the process of including differences orients and elaborats new knowledge and learning possibilities.
\end{abstract}

Keywords: Inclusion. Interculturality. Decoloniality.

INCLUSIÓN, INTERCULTURALIDAD Y DECOLONIALIDAD:

Cuando las cuestiones de raza, género y clase social interrogan las prácticas de enseñanza

\title{
RESUMEN
}

Este artículo pretende discutir los conceptos de inclusión, interculturalidad y decolonialidad basados en situaciones experimentadas por dos profesores de artes visuales, que buscan en sus contextos pedagógicos fomentar la reflexión de sus estudiantes para congelar las prácticas culturales de subalternación. La 
metodología utilizada es la investigación de acción, ya que es a partir de las situaciones emergentes en el aula que se establecen las categorías de investigación y la acción de intervención que pueden causar cambios en los sujetos, promoviendo la inclusión y el respeto por las diferencias. De lo anterior, se puede concluir que en el imaginario social que aún prevalece en la sociedad brasileña, todavía existe una manera difícil de crear conciencia sobre los problemas raciales y cómo se incluyen en los planes de estudio y las prácticas de los docentes de educación básica. Por lo tanto, defendemos la importancia de cuestionar y negar visiones congeladas y discursos sobre raza y género en el entorno escolar, sea cual sea el rango de edad de los estudiantes, porque se trata de promover la desidentificación. La promoción del reconocimiento de las diferencias presentes en la vida escolar diaria debe entenderse como una posibilidad de enriquecer el conocimiento e intercambiar experiencias escolares. Con este fin, debe haber una revisión constante de las relaciones entre sus actores, la selección de currículos y la didáctica en las escuelas para romper con el universalismo y el eurocentrismo, de modo que el proceso de inclusión de diferencias orientes y elabore nuevos conocimientos y nuevas nociones. posibilidades de aprendizaje.

Palabras clave: Inclusión. Interculturalidad. Decolonialidad.

\section{INTRODUÇÃO}

A sociedade atual está marcada pelo entrecruzamento de diversas questões socioculturais como: relações raciais e étnicas, de gênero, de sexualidades, pluralismo religioso, classe sociais, conflitos de gerações, de culturas infantis e juvenis. Estes aspectos têm provocado uma série de discussões, gerando polêmicas e debates incitados por diversos casos de intolerância, preconceito e discriminação em relação a determinados grupos sociais. Ao mesmo tempo, estas disputas vem conclamando a emergência de iniciativas visando a construção de uma sociedade mais justa e democrática que reconheça, respeite e valorize as diferenças.

Como reflexo deste processo, as escolas brasileiras também são marcadas por tensões, conflitos e a constante demanda por diálogos e negociações. Assim, o objetivo central deste texto é discutir a interculturalidade e a decolonialidade como possibilidades de se promover a inclusão e a construção de ambientes escolares plurais. A fim de fomentar as análises a partir de Bardin(2011), serão apresentadas práticas docentes realizadas por um professor e uma professora de artes visuais do ensino fundamental (anos iniciais e finais) atuantes na rede pública de ensino os 
quais discutem temas como raça e gênero em suas classes a partir de uma perspectiva intercultural.

Optou-se pelas abordagens metodológicas da pesquisa-ação, considerando que seus mecanismos permitem a reflexão e uma possível transformação do contexto pesquisado (FRANCO, 2005; IVENICKI; CANEN, 2016; THIOLLENT, 2011). Nesta perspectiva, esta metodologia tem se revelado como um importante caminho para a realização de pesquisas que busquem refletir sobre a prática pedagógica e, ao mesmo tempo, promover intervenção no cotidiano e provocar mudanças de entendimento e respeito às diferenças culturais e coloniais a partir de uma ação sistemática.

\section{ENTRECRUZAMENTOS TEÓRICOS}

Ao se pensar uma prática pedagógica ou pesquisa pelo viés intercultural é importante compreender que o professor/pesquisador não é neutro, mas, sim, um sujeito possuidor de um universo cultural, identidades e visão de mundo que interferem no desenvolvimento da pesquisa (IVENICKI; CANEN, 2016). Nesta perspectiva, a visão intercultural pode promover o diálogo entre grupos sociais, o reconhecimento do outro e, principalmente, contribuir para problematizar a escola e seus múltiplos atravessamentos culturais e os processos de inclusão/exclusão. A fim de fomentar este debate, cabe apresentar o que se entende, neste artigo, por inclusão:

Constitui-se um direito de TODOS, sendo dever da escola e dos educadores firmar este compromisso, por meio da promoção e criação de currículos, práticas e espaços que permitam o desenvolvimento de ações que contribuam para a remoção de barreiras na aprendizagem e para a formação de uma sociedade verdadeiramente democrática (XAVIER, 2009, p. 22)

Para muitos autores (SANFELICE, 2006; BUENO, 2006; BOLDT; KROHLING, 2007), é impossível falar de processos inclusivos sem refletir sobre exclusão. Para estes teóricos, por mais que os modelos de inclusão avancem, sua efetivação esbarra na impossibilidade de incluir quando a sociedade exclui em um movimento cíclico pendendo mais para o segundo do que o primeiro. (BOLDT; KROHLING, 2007) Portanto, a inclusão é entendida dentro 
de uma "dialética exclusão/inclusão", no qual se relacionam indivíduos, sociedades, costumes, processos culturais, políticas instituídas e práticas que dialogam de maneira dialógica e complexa (SAWAIA, 1999).

As escolas desempenham papel central na construção identitária dos sujeitos, assim, é papel da escola incluir, mas, antes de tudo, problematizar, os processos oriundos dele, garantindo espaço para a escuta e a reflexão de todos, em prol de instituições escolares mais plurais. (SANTIAGO; MELO, 2017)

Segundo King e Schneider (1999), os/as docentes são responsáveis pelo que escolhem ou não ensinar às crianças. Assim, suas escolhas dizem muito sobre o que valorizam, o que temem e como esperam que esses valores sejam adotados por seus/as alunos/as. Contudo, não se trata somente introduzir um novo conhecimento ao currículo. A questão central é problematizar o conhecimento inscrito, desestabilizar os saberes binários e as verdades construídas sobre gênero, sexualidades, raça, classe social.

Neste sentido, concorda-se com Silva Junior e Ivenicki (2019) quando afirmam que cada sujeito social é marcado por diversos atravessamentos e subjetividades - raça, gênero, sexualidade, classe social, entre outros. Há a crença de que, para trabalhar com estas questões no cotidiano escolar, seja útil recorrer ao conceito de intersecionalidade, criado pela jurista negra estadunidense Kimberlé Crenshaw em 1989. Este conceito permite trabalhar a intersecção entre diversas áreas do conhecimento dos estudos de gênero, das relações etnicorraciais ao interculturalismo. A intersecionalidade dos termos ganha adequação para a realidade social brasileira, uma compreensão desses processos que se inter-relacionam torna-se indispensável para uma melhor reflexão e atuação dos diversos segmentos da sociedade que buscam consolidar a democracia a partir da redução das desigualdades sociais, de gênero e raça (CRENSHAW, 2004).

\section{Reflexões sobre a perspectiva intercultural}

Deve-se observar que os termos interculturalismo e multiculturalismo têm sido usados em diferentes contextos, o primeiro sendo mais comum na Europa e na literatura latino-americana e o segundo em textos anglo-saxões. 
Apesar de haver discussões metalinguísticas com relação a tais categorias, não se pretende neste artigo fazer uma síntese destas diferenciações, deseja-se apenas acentuar aqui a polissemia do termo.

Neste sentido, o multiculturalismo tem se configurado como um campo teórico, prático e político que busca respostas às diferenças culturais para pensar em uma educação que reconheça e valorize a pluralidade no contexto escolar (CANDAU, 2008, 2010; CANEN, 2008, 2009; CANEN; XAVIER, 2012; MCLAREN, 1997, 2000a, 2000b). Este campo se refere à compreensão da sociedade formada por identidades plurais, com base na diversidade de classe social, gênero, etnia, raça, padrões culturais e linguísticos, assim como outros marcadores identitários. (CANEN, 2009; IVENICKI; XAVIER, 2015). Na busca de aproximar a interculturalidade do contexto educacional, Candau (2008) relaciona esta vertente ao multiculturalismo aberto e interativo. Ou seja, aquela vertente que privilegia a hibridização, que articula políticas de igualdade com políticas de identidade.

É relevante destacar que conceito de interculturalidade surgiu na América Latina, nos anos 70. Apesar de, inicialmente, estar diretamente relacionado à educação indígena, esse conceito é utilizado para se pensar outras questões sociais, tais como a questão do negro e da educação popular. Segundo Walsh (2007, 2009a, 2009b), esta perspectiva nasceu das lutas dos grupos e movimentos sociais e políticos ancestrais e suas demandas por direitos, reconhecimento e transformação social.

\section{A formação docente intercultural}

Alguns autores vêm propondo discussões no que se refere ao interculturalismo e à formação docente (CANEN; SANTOS, 2009; CANEN; XAVIER, 2005; IVENICKI et al, 2015). Neste sentido, a formação de professores interculturalmente conscientes é uma demanda que não deve ser ignorada, sendo necessário:

formar profissionais da educação interculturalmente orientados, conscientes da necessidade de promover um ensino culturalmente sensivel que considere as perspectivas dos alunos provenientes de 
diversos grupos culturais e com identidades múltiplas de gênero, raça, padrões linguísticos e outras (AKKARI; SANTIAGO, 2010 apud SANTIAGO et al, 2013, p. 24)

A promoção do reconhecimento das diferenças presentes no cotidiano escolar deve ser entendida como possibilidade de enriquecimento dos saberes e trocas de experiências escolares. Para tanto, as instituições escolares necessitam de uma constante revisão das relações entre seus atores, da seleção de currículos e da didática para que estes rompam com o universalismo e o eurocentrismo, de maneira que o processo de inclusão das diferenças oriente e elabore novos saberes e possibilidades de aprendizagem. (SANTIAGO et al, 2013; CANDAU, 2012)

Porém, não se pode esquecer que o espaço escolar brasileiro vem sendo marcado historicamente como legitimador de práticas classificatórias e excludentes que, de acordo com suas identidades e diferenças, definem quem está dentro e quem fica de fora (SANTIAGO et al, 2013). Cabe aqui ressaltar que identidade não é o oposto da diferença, ela é produto da diferença. Assim, por meio de processos de criação sociais e culturais, também presentes na escola e mediadas pelas relações de poder, identifica-se, em nossa sociedade, processos hierárquicos que buscam a essencialização e a homogeneização de identidades, favorecendo aquelas compreendidas como aceitáveis. Deste modo, a defesa intercultural e o paradigma pós-moderno não é a apenas a do direito a igualdade, pois essa pode ser compreendida como reducionista, mas a do direito a "sermos iguais sempre que a diferença nos inferioriza e o direito de sermos diferentes sempre que a igualdade nos descaracteriza" (SANTOS, 1999 apud SANTIAGO et al, 2013, p. 37)

$\mathrm{Na}$ pós-modernidade, as identidades são compreendidas como múltiplas e relacionais, além de transitórias e com potencialidades estratégicas. São assumidas pelos indivíduos e seus grupos sociais de diversas formas e em diversos contextos de acordo com o que se pretende construir discursivamente em determinado momento para determinado público. 
Os autores deste artigo, tal como Santiago e al. (2013, p.41), acreditam que "escola não pode se omitir no papel de problematizar as relações de poder, assim como de promover a negociação e o diálogo com os processos de diferenciação, que produzem aproximações e distanciamentos identitários". A compreensão da diferença como elemento constituinte do indivíduo e a educação enquanto direito são desafios que devem ser articulados pela escola em prol de práticas não homogeneizadoras e monoculturais.

Assim, segundo uma perspectiva intercultural, o processo de formação docente assume grande centralidade no processo de reestruturação das escolas da educação básica (SANTIAGO et al, 2013). O currículo desenvolvido na formação destes docentes possui relação direta com a orientação político-pedagógica assumida por eles em suas salas de aula.

Para Canen e Xavier (2005), a formação deve ser capaz de possibilitar ao educador um olhar sensível às diferenças e às múltiplas identidades presentes na escola, pois este é um espaço de crítica e de produção cultural. As autoras supracitadas defendem $\circ$ modelo de professor pesquisador "como um profissional reflexivo que assume a postura de constante reflexão crítica sobre a prática pedagógica, atuando ativamente na construção de seu conhecimento pedagógico", sendo este modelo formativo um possível caminho para a transformação da desigualdade educacional (CANEN; XAVIER, 2005, p. 335)

De acordo com Stühler e Assis (2009), para entender a complexidade do ambiente intercultural por onde transitam alunos e professores é necessário compreender as relações interpessoais, o espaço educacional, a cultura escolar estabelecida, o currículo e as identidades em jogo, para se repensar a escola como espaço por si heterogêneo, intercultural e criativo.

Para tanto, este artigo defende que o interculturalismo pode favorecer a emergência da democracia e da diferença como premissas incorporadas ao ato pedagógico, promovendo práticas pedagógicas e currículos mais inclusivos. 


\section{UM OLHAR SOBRE A PRÁTICA PEDAGÓGICA}

As análises que se seguem descrevem momentos de aulas de artes visuais 5 ocorridos em duas escolas públicas (uma municipal e outra federal). A primeira cena apresentada ocorreu em uma escola municipal no município de Duque de Caxias (periferia urbana em relação a cidade do Rio de Janeiro), com alunos/as do $6^{\circ}$ ano. É relevante ressaltar que o professor já estava trabalhando com a turma há alguns meses e, ao longo deste período (a partir de outras atividades propostas), tendo percebido a necessidade de discutir as questões de inclusão social (XAVIER, 2009) pelo viés raça, gênero e classe social. Isto porque, logo na primeira atividade do ano letivo (um autorretrato), ficou claro o quanto as meninas tinham dificuldade de se assumirem enquanto negras e como a questão do 'cabelo ruim', assim definido por elas, as incomodavam. Por outro lado, os meninos, em sua maioria, não se incomodavam e se autoidentificavam como negros devido ao processo de construção social relacionado aos homens vistos como fortes, másculos e extremamente hábeis nos esportes. Neste aspecto, é relevante destacar como o pensamento colonial (MIGNOLO, 2003) ao invadir o imaginário do outro, essencializou e criou estereótipos que o subalternizam, reduzindo diversos aspectos de suas subjetividades. O poder do opressor é tal que o subalternizado possui vergonha de apresentar publicamente suas subjetividades. Como no exemplo acima, emerge do campo atrelado a categorias primárias elencadas: o medo das meninas em falar sobre os cabelos ou de se assumirem como negras, sendo portanto, considerada como a primeira categoria secundária de análise (BARDIN, 2011).

A segunda categoria de análise parte de uma questão problema observada nas aulas de artes visuais de uma turma do $3^{\circ}$ ano do Ensino Fundamental, onde havia a discussão sobre a temática Arte e Ancestralidade.

\footnotetext{
5 Destacamos que os nomes de alunos/as e escolas são fictícios
} 
Nesta perspectiva, a temática escolhida era eixo curricular previsto pelo PPPI (Plano Político Pedagógico e Institucional) da escola. Os objetivos pretendidos destas aulas eram: investigar matrizes culturais que compõem a história dos estudantes e memória visual de suas famílias, bairros, comunidades; reconhecer a integração de várias etnias na formação do povo brasileiro; pesquisar obras de artistas homens e mulheres relacionadas à identidade e memória em diferentes contextos da arte e produzir artisticamente trabalhos com a temática da ancestralidade. É importante afirmar que, conforme Walsh (2009a) afirma, a interculturalidede crítica é um projeto a construir, trata-se de um projeto que busca problematizar as estruturas em busca de uma sociedade mais justa.

As observações feitas pela professora/pesquisadora das demandas dos/das alunos/as conduziram a discussão, para um tema não problematizado pelos alunos/as: o "lápis cor de pele". A fim de situar a questão, é importante esclarecer que a ideia de um único lápis cor de pele tem permeado o senso comum e faz parte do cotidiano de muitas pessoas que utilizam a nomenclatura "lápis cor de pele" para se referir a um único tom presente nas mais diversas caixas de lápis de cor, tintas e outros. De fato, esta cor é nomeada pela indústria como bege, rosa pálido, entre outras. Porém, culturalmente vem sendo utilizado como norma de representação, e entendido por muitos como "a cor de pele". Com isso, acredita-se que ao problematizar os múltiplos tons de cor da pele os estudantes estarão reconhecendo e valorizando as múltiplas culturas (CANDAU, 2008; SILVA JUNIOR e IVENICKI, 2019).

A partir destas cenas, pretende-se enfocar as questões étnico-raciais e de que formas o olhar intercultural (WALSH 2009a), e o decolonialismo (MilGNOLO, 2003, WALSH 2009b) atrelados ao currículo praticado podem propiciar espaços de ensino e aprendizagem mais críticos, democráticos e inclusivos.

\section{A cor: "o seu cabelo não nega"}


A primeira cena, como já mencionado, se passa em uma escola municipal de Duque de Caxias. O estudo da cor é um componente curricular que está previsto no programa da disciplina de artes visuais elaborado, naquela escola, para $\circ 6^{\circ}$ ano do Ensino Fundamental. Neste sentido, foi planejado pelo professor, um dos autores deste artigo, em conjunto com a orientadora educacional, as atividades do bimestre, incluindo vídeos, músicas e a teorização sobre cores. Para iniciar as discussões, o professor fez a apresentação do vídeo Vista minha peleb. Estavam presentes na sala 18 meninos e 10 meninas. Foi procurado deixar a turma bem à vontade, pediu-se para fazerem pipoca, o professor levou refrigerantes, tentando reproduzir uma sala de cinema. Antes de começar, foi feito o convite para assistirem ao filme e foi destacado que ele apresentava questões raciais muito interessantes, às quais os/as alunos/as deveriam prestar atenção.

Logo no início, foi sentido um certo estranhamento por parte da turma: risinhos, alguns meninos se movimentando excessivamente nas cadeiras. Contudo, ninguém se levantou ou saiu da sala durante a exibição. Não foram ouvidas piadas ou comentários ao longo dos 25 minutos aproximados de filme. Apenas foi destacado no diário de notas deste professor que, durante a exibição, "os meninos ficaram mais inquietos e agitados do que as meninas, que permaneceram em silêncio durante todo o vídeo".

Ao final, o aluno Endison comentou: "Nossa é muito estranho ver um filme assim, só negro". Foi analisado esta fala como sendo um instante de desestabilização do grupo, que não estava acostumado a ver filmes com protagonismo negro. Os/as aluno/as não tinham contato, em seu cotidiano, com negros/as em posição dominante. Em seu convívio diário, eles/as assistiam a negros/as recebendo ordens e trabalhando como empregados em funções subalternas. Talvez os/as negros/as melhor posicionados

\footnotetext{
6 Trata-se de um vídeo de 2003, disponível na internet e patrocinado pelo CEERT (Centro de Estudos das Relações de Trabalho e Desigualdades), com roteiro de Joel Zito Araújo e Dandara e direção do primeiro. A produção destina-se à discussão das questões raciais e apresenta uma inversão de papéis. Aqui os negros são a classe dominante e os brancos são ex-escravos, assim como os países pobres são Alemanha e Inglaterra, enquanto Moçambique é um país rico.
} 
socialmente fossem os/as próprios professores/as da escola. Aqui é relevante destacar como o pensamento colonial que inferiorizou o negro e reduziu a papeis sociais de subalternos continua presente no imaginário de muitos alunos (WALSH, 2009a; SILVA JUNIOR e IVENICKI,2019). Ao mesmo tempo que nos mostra a necessidade de problematizar e interrogar estas visões essencializadas (CANEN, 2008; CANDAU, 2012).

Contudo, antes que o professor pudesse dizer algo, o aluno Andrew falou: "Você está sendo preconceituoso, tem que saber respeitar". Dalila rapidamente interveio: "É que.... é diferente, a gente não tá acostumada a ver filme assim". Para problematizar esta fala, o professor perguntou: "Assim como?" Por um minuto, silêncio na turma; depois de algum tempo, Vitória se posicionou e disse: "Com negros fazendo papéis de ricos... E só com eles tendo dinheiro ...Olha as novelas são muito poucos ... Nem sei". A fala desta aluna reafirma que os/as alunos/as não possuem referencial de negros no poder, principalmente no que se refere a intelectuais7.

A aluna Vitória destacou: "Mais eu acho que o vídeo também é preconceituoso porque só mostra a maioria de negro. Não resolve deste jeito. Tem que ter os dois vivendo iguais... com dinheiro e situação". Este foi um ponto relevante, em que a aluna buscava a valorização do convívio entre raças diferentes, uma discussão muito presente nas vertentes multiculturais pós-coloniais, interativas, críticas e interculturais (CANDAU, 2010, 2012; CANEN, 2007, 2008, 2009; MCLAREN, 1997, 2000a).

Entretanto, o aluno Wallace entrou na conversa e citou um outro aspecto do vídeo: "As meninas são todas com cabelo durão, não são bonitas". Trata-se de um tema tabu entre as adolescentes negras, pois as questões relativas ao cabelo fazem parte do cabedal de discursos emancipatórios das mulheres negras. Todo o processo de colonização valorizou os modelos de beleza da mulher branca; em consequência, o

\footnotetext{
7 Tem-se a consciência que cabe aos/as professores/as, ampliar este repertório discente, mostrando diversos/as intelectuais negros/as e desestabilizando as expectativas de papéis sociais para negros e negras. Como o professor da turma em questão, também autor deste texto é negro, acredita-se que é possível considerá-lo um exemplo de desestabilização, já que ele circula em meios diversos, sendo modelo diverso de atuação e convívio para seus alunos, também negros.
} 
modelo de cabelo socialmente desejado é o comprido e liso. Deste modo, o professor argumentou, que ele [Wallace] não achava as meninas bonitas porque somos regidos pelos padrões de beleza do modelo branco europeu, o qual exclui o cabelo afro ou crespo dos padrões desejáveis.

Conforme demonstra Costa de Paula (2010), a mulher negra pode se mostrar insegura em relação à própria imagem por causa do cabelo. De fato, a aluna Joyce comentou: "É por isso que temos que alisar os cabelos, senão todo mundo acha feio". lara se defendeu: "Eu não gosto de cabelo escorrido, gosto do meu cacheado, não me importo com o que os outros falem." "Mais você alisa do mesmo jeito, lara seu cabelo é ruim e o dela é implante", comentou Natalia. A partir daí, os comentários sobre cabelos tomaram uma grande proporção, com cada uma destacando como alisa o cabelo e a vantagem que algumas brancas têm de ter cabelo liso. Entendese que, no caso do cabelo, a mulher negra e pobre sofre ainda mais que aquelas que possuem mais recursos econômicos que permitem se submeter a tratamentos de beleza e assim modificar sua imagem e trabalhar a autoestima. Há, deste modo, um duplo processo de exclusão que se dá não apenas pela questão racial, mas que esbarra no poder aquisitivo e na classe social.

A maioria dos meninos não se interessou em participar da discussão. Apenas as vozes de Wallace, Mauro, Endison e Andrew aparecem na gravação, mesmo assim na forma de risos. Um dos poucos momentos em que se ouve a voz do Wallace é para dizer que "pegar em cabelo liso é mais gostoso... é bom para ficar..." e fez o gesto como se estivesse beijando e passando as mãos nos cabelos da outra pessoa. Uma fala como essa, vinda de um menino considerado bonito pelas alunas da turma, tente a desestabilizar e inferiorizar as meninas negras, pois, as coloca como menos desejáveis ou interessantes ao olhar dos alunos da turma.

O professor desde a primeira cena aproveita a discussão para problematizar o conceito de beleza da mulher e as razões por que, historicamente, o cabelo liso é considerado cabelo bom. Resolve perguntarIhes quais os adjetivos atribuídos a um cabelo considerado duro, e lista as 
respostas no quadro: "Cabelo bombril, ruim, espeto do inferno, cabelo do diabo, sarará crioulo, nega maluca, coisa ruim, carapichicho, ..." - todos os termos observados são negativos e refletem estereótipos raciais, relativos aos negros e negras construídos ao longo dos anos. Aqui a proposta era problematizar os discursos essencializados sobre raça (BARNARD, 2004; SOMERVILLE, 2000) e trazer à tona que determinadas características são traços das múltiplas identidades de raça (CANDAU, 2008; CANEN, 2009). Por isso, foi solicitado à turma que refletisse sobre todos aqueles nomes escritos no quadro, e sobre como eles depreciavam e subalternizavam o/a outro/a. Foi observado que, desde o processo de colonização, o/a negro/a veio sendo construído/a como inferior, e que as diferenças foram marcadas em relação ao branco/a (WALSH, 2009a).

Foi mostrado que enquanto ser branco/a significa ser bonito/a, ser negro/a corresponde a ser feio/a; que o cheiro do branco/a é bom, ao passo que o do/a negro/a fede, entre outras comparações que quem é negro/a conhece muito bem, incluindo todos aqueles atributos relativos ao cabelo, especialmente quando atribuídos à mulher negra.

Naquela ocasião, o objetivo era mostrar como o/a colonizado/a foi marcado/ pelas relações de poder que o/a construíram (QUIJANO, 2007) e como negros e negras, carregam esses discursos que se internalizam no corpo e que causam um sentimento de inferiorização. Foi chamada a atenção para o fato de que já era hora de repensar as formas como historicamente o povo brasileiro fora construído.

Convocou-se a turma a pensar na história do Brasil desde a chegada dos portugueses, tentando trazer à tona a questão da diferença colonial (MIGNOLO, 2003; OLIVEIRA, 2010). Destacou-se como o/a negro/a foi identificado/a e subalternizado/a ao longo dos anos, e como era importante pensarmos nestas questões para criarmos/desenvolvermos maneiras positivas de identificação (BARNARD, 2004; SOMMERVILLE, 2000). A proposta era a de buscar reconhecer que todos aqueles adjetivos citados no início da conversa serviam para desqualificar e inferiorizar uma raça, atacando diretamente a autoestima das pessoas. 
Era então necessário realizar a desidentificação (MUÑOZ, 1999), ou seja, livrar-se dessas formas pejorativas com que foram comparados e nomeados enquanto negros e negras. Enfatizou-se que, apesar de estar se falando principalmente de cabelos, a mesmo se estendia a todas as condições que reduzem os/as negros/as a inferioridade em diversos aspectos de suas subjetividades. É importante destacar, que o professor, um dos autores deste artigo, assim como seus/suas alunos/as, também estava experimentando novas formas de identificação que não as relacionadas aos processos de determinismo biológico ou social (BARNARD, 2004; MUÑOZ, 1999; SOMMERVILLE, 2000). Deste modo, a reverberação das discussões estabelecidas impactou a todos/as em direção a uma tentativa de ruptura de práticas culturais subalternizantes.

A turma ouviu o professor em silêncio, salientando que se tratava de uma questão cultural e que o vídeo mostrava isso. Lembrou-se que, se vivêssemos naquela sociedade apresentada no filme, certamente os padrões de beleza seriam diferentes daqueles que discutiam no momento; e que as relações de poder seriam outras, sob as quais todas as diferenças seriam postas de maneira que a raça negra fosse vista como superior: mais inteligente, mais bonita etc.

Em seguida, retomou-se a discussão dos cabelos. O professor falou sobre algumas mulheres negras famosas que não os alisavam - como as atrizes Sheron Menezes e Luci Ramos, a jornalista Majú (Maria Julia Coutinho) e a cantora Luciana Melo - e como o público, de um modo geral, as achava lindas. Ao mesmo tempo foi mostrado que havia outras que alisavam os cabelos e que as pessoas também achavam lindas - como as jornalistas Gloria Maria e as atrizes Camila Pitanga e Thais Araújo -, e ainda como as que usavam belos apliques - como a atriz Cris Vianna, que todos/as conheciam por ter sido madrinha de bateria da escola de samba da cidade.

Com isso, foi reforçada a importância de se valorizar as diferenças e a beleza da mulher negra, com destaque para a questão dos cabelos, uma vez que eles marcam nossa aparência e funcionam como um cartão de 
visitas. No caso das meninas, com base em Costa de Paula (2010), o professor afirmou que a inquietação com os cabelos é comum a todas as afrodescendentes: algumas preferem alisá-los, outras os deixam cacheados ou naturais, outras os raspam; no entanto, o que todas querem são cabelos bonitos que as agradem e as façam se sentir seguras e lindas com a própria aparência. Nesse dia o professor conseguiu chamar atenção da turma para as questões raciais e mostrar outras possibilidades de se constituir uma sociedade, independente de serem negros/as ou brancos/as. Vale mencionar que esta discussão foi retomada na semana seguinte e em outros momentos do ano letivo, uma vez que não se trata de um assunto totalmente superado, mas que está presente nos enfrentamentos cotidianos daquele grupo de adolescentes.

Em paralelo as questões discutidas nesta primeira cena, considera-se relevante resgatar a dissertação de mestrado de Silva (2017), que se propõe a discutir a utilização dos livros de histórias infantis que chegavam até a creche filantrópica por ela pesquisada. Apesar de não se concentrar no ensino de artes visuais, as análises trazidas pela autora demonstram que desde a Educação Infantil, a questão da discriminação por cor e raça e o fortalecimento de padrões de beleza colonialistas se impõem desde cedo na educação.

As histórias lidas na contação, em colaboração com alguns discursos e "verdades" transmitidas para e pelas crianças revelaram um trabalho de descaracterização de etnia negra, reafirmado pelo embranquecimento das heroínas, príncipes e princesas presentes nos livros adotados pela creche para os cantinhos de leitura. (SILVA, 2017)

Assim, Silva (2017, p. 99), defende a importância de se discutir:

os processos de valorização da identidade, no entanto, a escola deve se mostrar como um espaço democrático para promoção de práticas sociais contrárias a estigmas que excluem as manifestações heterogêneas que são encontradas no ambiente escolar. No entanto, para a escola ser tornar um espaço democrático, aberto a discussões que visam uma sociedade igualitária, é preciso da ajuda, não somente por parte da comunidade escolar, mas de todo um corpo da sociedade. 
Neste sentido, no âmbito de uma creche ou no âmbito do sexto ano do Ensino Fundamental observa-se a mesma questão, o binômio paradoxal inclusão/exclusão. A escola que deveria incluir, dependendo de como seus profissionais foram formados e se constituíram como sujeitos, pode ser aquela que exclui. Assim, como registrado pelo imaginário social dos contextos escolares apresentados, enraizado pelo colonialismo histórico, ser branco é, ainda, o padrão procurado e reconhecido como melhor e mais bonito.

\section{"Lápis Cor de Pele": Polvo8 e Humanae Project9}

Este segunda cena de análise, parte da necessidade de professora de artes visuais de colégio federal situado na cidade do Rio de Janeiro, em problematizar com seus alunos/as do terceiro ano do Ensino Fundamental o dito "lápis cor de pele10". Em suas observações, foi constatado pela professora que muitos alunos/as, independentemente de sua cor de pele, faziam referência a um único lápis ou tinta como sendo "A" cor de pele. Ela observou a dificuldade de alguns em se representarem segundo suas características pessoais, mesmo quando solicitada a produção de um autorretrato, questão esta também observada no relato anterior. Além disso, havia uma aparente normatização sobre 'a cor de pele' a ser utilizada, sendo a maior parte das produções coloridas com um mesmo tom de lápis de cor, o qual eles chamavam de lápis cor de pele. É relevante destacar como o discurso aparentemente ingênuo de uma criança ao nomear um único tom de cor como "o tom de pele" certo, desejável, possível, ou aceitável, acaba por excluir como possibilidades de representação todas as outras cores de pele ou raça.

\footnotetext{
8 Polvo (2014), obra de Adriana Varejão artista brasileira. Para mais informações sobre a artista: http://www.adrianavarejao.net/br/home Acesso em 29 de julho de 2019.

9 Humanae Project (2019), obra de Angélica Dass em andamento. Para mais informações sobre a artista:

https://www.angelicadass.com/ Acesso em 29 de julho de 2019.

10 O termo lápis cor de pele é culturalmente utilizado no contexto pesquisado com a finalidade de denominar uma certa tonalidade de lápis de cor, giz de cera ou tinta guache a qual se aproxima ao rosa claro ou areia.
} 
Deste modo, a docente estruturou suas discussões com a turma a partir dos seguintes conteúdos: a miscigenação do povo brasileiro e matrizes culturais, a produção de pigmentos, o conceito de tom e de tom de pele, a discussão sobre as identidades raciais (MUNOZ, 1999; SOMMERVILLE, 2000) percebidas e vividas pelo coletivo dentro e fora da escola e a discussão do tema cores de pele por artistas contemporâneas brasileiras. A fim de fomentar a educação do olhar, respeito pela diversidade e a valorização da autoimagem dos alunos/as em busca da construção de uma sociedade mais democrática (CANEN, 2008; WALSH 2009a, 2009b) foram trabalhadas as obras de Angélica Dass (HUMANAE PROJECT, 2019) e Adriana Varejão (POLVO, 2014), artistas brasileiras contemporâneas as quais discutem o interculturalismo, o hibridismo e a alteridade, a partir de suas obras.

Para o início do projeto, a professora levou para a aula o vídeo "Lápis cor de pele"1112, o qual aborda a temática a partir do olhar da criança. A roda de conversas iniciada foi de grande valia para despertar nos alunos/as a seguinte indagação: "Qual é a minha cor de pele?". Outra demanda do grupo, foi a necessidade de nomear o lápis e a tinta em questão de outras formas, que passariam, daquele momento em diante, a ser chamada de "rosinha" ou "salmão", assim buscando problematizar e desconstruir o termo "cor de pele". (BARNAD, 2004; CANDAU, 2012).

Com a atividade de pesquisa plástica, as turmas foram convidadas a construir com a tinta guache suas próprias paletas de cor de pele, misturando pigmentos e explorando processos de reconhecimento e identificação, deste modo, foi estabelecida a reflexão sobre as identidades e diferenças. Este momento, apesar de ainda inicial, mostrou-se como caminho possível para o desenraizamento de práticas colonialistas (WALSH, 2009a; OLIVEIRA, 2010), voltadas para a homogeneização e silenciamento das alteridades e emergência de outras formas de identificação (BARNARD,

\footnotetext{
11 O vídeo Lápis cor de pele está disponível em: <https://www.youtube.com/watch?v=6ZsWWe3YEDE> Acesso em 29 de juho de 2019.

12 Além do vídeo utilizado pela docente, encontra-se disponível na internet o curta "Dudu e o Lápis cor de pele"e o livro "Lápis Cor De Pele" da autoria de Daniela de Brito.
} 
2004; MUÑOZ, 1999; SOMMERVILLE, 2000). Além de se configurar como estratégia condizente com a faixa etária e com as realidades vividas por aquele grupo de alunos.

Nas quatro aulas que se seguiram, foram apresentadas as obras de Adriana Varejão (POLVO, 2014) e Angélica Dass ${ }^{13}$ (HUMANAE PROJECT, 2019), tendo como enfoque o contexto de produção e reflexão das artistas e os pontos de partida para suas produções.

Para Adriana Varejão (2018), a mestiçagem é um tema recorrente em sua obra, sendo o hibridismo uma de suas inúmeras referências. A artista busca olhar não apenas as histórias mencionadas pela história oficial, mas também para as histórias escondidas, com o objetivo de derrubar conceitos e desenraizar subjetividades e práticas culturais subalternizantes. É neste contexto de reflexão sobre a questão de raça no Brasil que a autora desenvolve a série Polvo (2014), e esclarece:

Como a categoria de raça é subjetiva, o trabalho também desmascara a hipocrisia cotidiana que permeia nossas relações. Vivemos em uma sociedade na qual quanto mais rico, mais branco. A cor vira um dispositivo de poder diário que coloca as pessoas 'em seu devido lugar'. O projeto Polvo reitera que cor atua como linguagem e léxico, além de instigar o expectador a repensar suas próprias classificações cromáticas e os processos sociais que por meio delas se expressam (VAREJÃO, 2018, p. 1)

Assim, o trabalho com as turmas foi direcionado para $\circ$ olhar para $\circ$ outro e para o reconhecimento de que todos são diferentes e que necessitam ser respeitados e entendidos como tal, como sugerem Candau (2010) e Canen e Xavier (2005). Trazer para o universo infantil questões de raça e promover a reflexão sobre os essencialismos e preconceitos inculcados é um dos grandes caminhos para a construção de um ambiente escolar no qual o decolonialismo possa se fazer presente, colaborando para

13 As turmas assistiram a conferência do TED dada por Angélica Dass, para melhor compreender o contexto de produção de suas obras e as indagações pessoas da artista sobre as questões de raça e interculturalidade. Disponível em : <https://www.ted.com/talks/angelica_dass_the_beauty_of_human_skin_in_every_color?lang vage=pt-br> Acesso em 29 de julho de 2019. 
a inclusão de contextos raciais antes negados e exclusão de práticas subalternizantes.

Já o Humanae (DASS, 2019), um projeto desenvolvido por Angélica Dass, tem por objetivo inventariar a paleta da pele das pessoas fotografadas a partir do sistema de cores PANTONE ${ }^{14}$, discutindo questões relativas à discriminação, à quebra de estereótipos e os preconceitos que influenciam nossas ações. A artista busca provar, assim como Varejão (2018), que a classificação de branco e preto é uma construção social, permeada de preconceitos históricos que refletem em situações cotidianas. Assim como Mignolo (2003), afirma, esta origem colonialista precisa ser discutida pela sociedade também pela escola, já que essa é um dos espaços prioritários de construção de significados para crianças e adolescentes. Sobre o impacto de sua obra, a artista registra que:

O grande impacto que eu tive foi através da educação, desenvolvendo o Humanae com os educadores, (...) E os educadores dizem "Em minha aula, nunca mais um aluno falou "lápis cor de pele". E se alguém fala, os colegas corrigem". Isso é muito importante, porque eles se corrigem, corrigem os pais, os amiguinhos. Veja quanta cor da pele existe no mundo.(DASS, 2019, p. 1)

É interessante notar a preocupação de Dass (2019), com o desdobramento de seu trabalho para o âmbito escolar, a artista reconhece a limitação de sua circulação nos espaços culturais em que expõe e busca de diversas maneiras atingir outros públicos, seja pela postagem de suas imagens em espaços públicos, seja pela ida a escolas para oficinas com alunos/as, ou pela formação de professores/as multiplicadores de suas propostas.

No decorrer do tempo de projeto, foi notado pela professora uma mudança de postura dos/as alunos/as no que se refere ao uso dos tons de pele, além da valorização das diferenças, em contraposição às práticas homogeneizadas e pouco reflexivas observadas inicialmente (SILVA JUNIOR, IVENICKI, 2019; CANEN, 2008). Como Dass (2019), afirma no trecho citado o

\footnotetext{
14 A escala Pantone é um sistema de cor criado por Pantone Inc. o qual consiste na identificação precisa as cores a partir de uma numeração. De largo uso industrial, em especial gráficas e têxteis.
} 
uso do nome "lápis cor de pele" foi aos poucos sendo substituído pelo grupo, em um processo de mudança da própria cultura escolar.

\section{CONCLUSÃO}

A partir do exposto pode-se afirmar que, no imaginário social ainda vigente na sociedade brasileira, há um caminho difícil de conscientização em relação às questões raciais e de que maneira estas se veem incluídas nos currículos e práticas dos docentes da educação básica.

Neste sentido, o artigo discute a interculturalidade (CANDAU, 2008; CANEN, 2008; WALSH, 2009a) e a decolonialidade(MIGNOLO, 2003; QUIJANO, 2007) e sua contribuição para o desenvolvimento de práticas pedagógicas inclusivas no currículo escolar. Assim, temas relativos à raça interseccionadas (CRENSHAW, 2004), principalmente com questões de classe social e gênero foram trazidas por alunos/as de diferentes escolas e problematizadas por seus docentes durante as aulas de artes visuais. Vale retomar o caso do cabelo para as meninas trazido pelo primeiro caso.

Os/As autores/autoras deste texto defendem a importância de questionar e desessencializar visões e discursos congelados sobre raça e gênero no ambiente escolar, seja qual for a faixa etária dos alunos, pois, trata-se de promover a desidentificação (MUÑOZ, 1999). Em outras palavras, fazer com que alunos/as reflitam sobre determinados conceitos que foram naturalizados ao longo dos tempos, como, por exemplo, as expressões "cabelo ruim", "coisa está preta" e "lápis cor de pele". Com isso, assume-se a responsabilidade de fazer circular novos discursos em sala de aula, uma vez que em classe os/as professores/professoras são responsáveis pelo que escolhem valorizar e pelo que escolhem silenciar. (KING; SCHNEIDER, 1999) Pois, promover ou não o interculturalismo, pensar ou não processos de inclusão, problematizar raça, gênero e questões de classe está nas mãos desses/dessas docentes.

Ao trabalhar a partir da proposta de inclusão das diferenças pelo viés intercultural, outra questão veio à tona, a necessidade de ampliar a noção de conhecimento dentro dos currículos propostos. Dito em outras palavras, a 
ideia é pluriversalizar o conhecimento, nas palavras de Mignolo (2003), trazendo a visão de sujeitos dentro do conjunto, pensando em interculturalidade e decolonialidade na produção de conhecimento.

\section{REFERÊNCIAS}

BARDIN, L. Análise de Conteúdo. Lisboa, Portugal: Edições 70, 2011.

BARNARD, I. Queer race: cultural interventions in the racial politics of queer theory. Nova York: Lang, 2004.

BOLDT, R.; KROHLING. A., A (IM)POSSÍVEL INCLUSÃO DO "OUTRO" NA SOCIEDADE EXCLUDENTE. Revista Intertemas, p. 141-162, 2007

BUENO, J. G.S. Processos de inclusão/excusão escolar, desigualdades sociais e deficiência. Pesquisa e educação especial: mapeando produções. Vitória: Edufes, p. 203-218, 2006

CANDAU, V. M. Multiculturalismo e educação: desafios para a prática pedagógica. In: MOREIRA, A. F. B.; CANDAU, V. M. (Org.). Multiculturalismo: diferenças culturais e práticas pedagógicas. Petrópolis: Vozes, 2008. p. 13-37.

CANDAU, V. M. Sociedade, educação e cultura(s). 3. ed. Petrópolis: Vozes, 2010.

CANDAU, V. M. Sociedade multicultural e educação: tensões e desafios: In: CANDAU, V. M. (Org.). Didática crítica intercultural: aproximações. Petrópolis: Vozes, 2012. p. 19-54

CANEN, A. O multiculturalismo e seus dilemas: implicações na educação.

Comunicação e Política, Rio de Janeiro, v. 25, n. 2, mai./ago., 2007.

CANEN, A. A educação brasileira e o currículo a partir de um olhar multicultural: algumas tendências e perspectivas. In: BARROS, J. F.; OLIVEIRA, L. F (Org.). Todas as cores na educação: contribuições para uma reeducação das relações étnico-raciais no ensino básico. Rio de Janeiro: Quartet, 2008. p. 59-79.

CANEN, A. Currículo, diversidade e formação docente. In: BARROS, R. M. de (Org.). Subjetividades e educação: conexões contemporâneas. Rio de Janeiro: Contra Capa, 2009.

CANEN, A; XAVIER, G. P. de M. Gestão do currículo para a diversidade cultural: discursos circulantes em um curso de formação continuada de professores e gestores. Currículo sem Fronteiras, [S.I.], v. 12, n. 2, p. 306-25, 2012 
CANEN, A.; XAVIER, G. P. de M. Multiculturalismo, pesquisa e formação de professores: o caso das diretrizes curriculares para a formação docente. Ensaio avaliação e Políticas Públicas em Educação, Rio de Janeiro, v. 13, n. 48, p. 333-44, jul./set., 2005.

COSTA DE PAULA, R. "Não Quero Ser Branca Não. Só Quero um Cabelo Bom, Cabelo Bonito" - Performances de Corpos/Cabelos de Adolescentes Negras em Práticas Informais. 2010. Tese (Doutorado em Linguística Aplicada) Universidade Estadual de Campinas - UNICAMP, SP, 2010.

CRENSHAW, K. W. A interseccionalidade na discriminação de raça e gênero. In: V.V.A.A. Cruzamento: raça e gênero. Brasília, DF: Unifem, 2004.

DASS, A. Humanae Project. Photography. Madrid, 2019.

DASS, A. Qual a cor da sua pele? Entrevista. Instituto Iberê Camargo, 29 de abril de 2019. Disponível em: http://www.iberecamargo.org.br/qual-a-cor-dasua-pele Acesso em 29 de julho de 2019.

FRANCO, M. A. S. Pedagogia da Pesquisa-ação. Educação e Pesquisa, São Paulo, v. 31, n.3, p. 483502, set./dez. 2005.

IVENICKI, A.; CANEN, A. G. Metodologia da pesquisa: rompendo fronteiras curriculares. Rio de Janeiro: Ciência Moderna, 2016.

IVENICKI, A; XAVIER, G. P. de M. Currículo multicultural e desafi o a fronteiras de exclusão: reflexões e experiências de construção coletiva docente. In: NASCIMENTO, A. C.; BACKES, J. L. (Orgs.). Inter/Multiculturalidade, relações étnico-culturais e fronteiras da exclusão. Campinas: Mercado das Letras, 2015.

IVENICKI, A. et al. Extensão Universitária, Multiculturalismo e Gênero na Formação Docente. Educação em Foco (Juiz de Fora), 19, 2015. 17-36.

KING, J. R.; SCHNEIDER, J. J. Locating a place for gay and lesbian themes in elementary reading, writing and talking. In: LETTS I. V, W. J.; SEARS, J. (Edits.). Queering elementary education: advancing the dialogue about sexualities and schooling. New York: Rowman \& Littlefi eld Publishers, 1999. p. 3-14

MCLAREN, P. A vida nas escolas: uma introdução à pedagogia crítica nos fundamentos da educação. Porto Alegre: Artes Médicas, 1997.

MCLAREN, P. Multiculturalismo crítico. 3. ed. São Paulo: Cortez/Instituto Paulo Freire, 2000a.

MCLAREN, P. Multiculturalismo revolucionário: pedagogia do dissenso para o novo milênio. Porto Alegre: Artes Médicas, 2000b. 
MIGNOLO, W. Histórias globais: projetos locais colonialidade, saberes subalternos e pensamento liminar. Belo Horizonte: UFMG, 2003.

MUÑOZ, J. E. Disidentification. Queer of color and performance of politics. Minneapolis: University of Minnesota Press, 1999.

OLIVEIRA, L. F. Histórias da África e dos africanos na escola: as perspectivas para a formação dos professores de história quando a diferença se torna obrigatoriedade curricular. 2010. 281 f. Tese (Doutorado em Educação) Pontifícia Universidade Católica do Rio de Janeiro - Rio de Janeiro, 2010.

QUIJANO, A. Colonialidad del poder y clasificación social. In: CASTROGÓMEZ, S.; GROSFOGUEL, R. (Org.). El giro decolonial. Reflexiones para una diversidad epistémica más allá del capitalismo global. Bogotá: Universidad Javeriana-Instituto Pensar / Universidad Central-IESCO / Siglo del Hombre Editores, 2007.

SANFELICE, J. L.; INCLUSÃO EDUCACIONAL NO BRASIL: LIMITES E POSSIBILIDADES. Revista de Educação PUC- Campinas. Campinas, n. 21 , p. 29-40, 2006.

SANTIAGO, M.; AKKARI, A.; MARQUES, L. P. Os caminhos do Interculturalismo no Brasil. In: Educação Intercultural: desafios e possibilidades.

Petrópolis: Ed. Vozes, 2013. p. 15-33.

SANTIAGO, M. C.; MELO, S. C., INCLUSÃO , ÉTICA E INTERCULTURALIDADE: a diversidade na educação pública brasileira. In: Universidade e Participação: inclusão, ética e interculturalidade. Org: Santos et. al. Curitiba: CRV, 2017

SAWAIA, B., As artimanhas da exclusão. Petrópolis: Ed. Vozes, 1999.

SILVA JUNIOR, P.M; IVENICKI, A. Entre sexualidades, masculinidades e raça: contribuições do multi/ interculturalismo para a prática pedagógica. Rev.

Tempos Espaços Educ. | São Cristóvão, Sergipe, Brasil, v. 12, n. 29, p. 125-144, abr./jun. 2019.

SILVA, S. A. de O. A roda de história na educação infantil: a narrativa no contexto da valorização da identidade negra, criatividade e autoria de pensamento. Dissertação (mestrado em Educação) - Universidade Federal do Rio de Janeiro, 2017.

SOMMERVILLE, S. B. Queering the color line: race and the invention of homosexuality in American culture. Durham: Duke University Press, 2000.

STÜHLER, G. D.; ASSIS, M. D. P. Relações interpessoais: construindo um clima institucional positivo na escola. In: CANEN, A.; SANTOS, A. R. Educação multicultural: teoria e prática para professores e gestores em educação. Rio de Janeiro: Ciência Moderna, 2009. 
THIOLLENT, M. Metodologia da pesquisa-ação. 18 ed. São Paulo: Cortez, 2011

VAREJÃO, A. Polvo. 2014.

VAREJÃO, A. P., por Adriana Varejão. Revista Philos.com, 2018. Disponível em: http://revistaphilos.com/2018/1 1/29/polvo-por-adriana-varejao/ Acesso em 29 de julho de 2019.

XAVIER, G. P. de M., Educação Inclusiva. In: Educação Multicultural: Teoria e Prática para Professores e Gestores em Educação. Org: CANEN, A.; SANTOS, A. R. Rio de Janeiro: Editora Ciência Moderna, p. 17- 40, 2009.

WALSH, C. Interculturalidad y colonialidad del poder. Un pensamiento y posicionamiento "otro" desde la diferencia colonial In: CASTRO-GÓMEZ, S.; GROSFOGUEL, R. (Org.). El giro decolonial. Reflexiones para uma diversidad epistémica más allá del capitalismo global. Bogotá: Universidad JaverianaInstituto Pensar/Universidad Central-IESCO /Siglo del Hombre Edits, 2007.

WALSH, C. Interculturalidad y (de)colonialidad: Perspectivas criticas Y políticas. Conferência Inaugural. XII Congresso ARIC, Florianópolis, Brasil, 29 jun. 2009a.

WALSH, C. Interculturalidade crítica e pedagogia decolonial: in-surgir, reexistir e re-viver. In: CANDAU, V. M. Educação intercultural na América Latina: entre concepções, tensões e propostas. Rio de Janeiro: 7Letras, 2009b.

Recebido em: 16 de julho de 2021.

Aprovado em: 11 de agosto de 2021. Publicado em: 17 de setembro de 2021. 